\title{
Estafilococos Coagulase Positiva em Amostras de Queijo Minas Frescal Vendidos em João Pessoa - PB
}

Winnie Alencar Luciano (I), Roberta Santos Lima (I), Maiara da Costa Lima (I), Rhayane Idalyne Carvalho (I), Eryka Maria dos Santos Alves (I), Jossana Pereira de Sousa (II), Thais Santana Ribeiro (I), Evandro Leite de Souza (I), Maria Lúcia da Conceição (I)

(I) UFPB - Universidade Federal da Paraíba (Cidade Universitária - João Pessoa - PB - Brasil CEP: 58051-900), (II) UFPE - Universidade Federal de Pernambuco (Cidade Universitária Recife - PE - CEP: 50670-901)

\section{Resumo}

O queijo minas frescal também pode ser classificado segundo a Agência Nacional de Vigilância Sanitária de duas formas: de alta umidade (46\%) ou de muita alta umidade (55\%) com bactérias lácticas abundantes e viáveis, que influenciam na proliferação de micro-organismos, em particular, Estafilococos coagulase positiva. Este trabalho teve como objetivo monitorar a presença de Estafilococos coagulase positiva em amostras de queijo minas frescal vendidos em João Pessoa - PB. Amostras de queijos mina frescal foram adquiridas cinco marcas denominadas como $\mathrm{R} 1(\mathrm{n}=4)$, R2 ( $n=3), R 3(n=2), R 4(n=2)$ e R5 ( $=3$ ) perfazendo 14 amostras, tendo-se como fator de exclusão produtos que apresentarem o mesmo lote, provenientes de alguns estabelecimentos comerciais da cidade de João Pessoa, Paraíba, Brasil. As amostras foram avaliadas quanto à presença das bactérias Estafilococos coagulase positiva, isolada pela técnica da

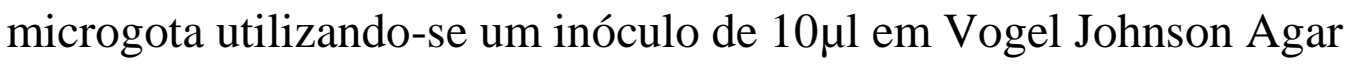
(Himédia, India) seguindo de incubação a $35\left( \pm 2^{\circ} \mathrm{C}\right)$ por $24-48$ horas. Após esse período de incubação, colônias típicas de Estafilococos foram isoladas e identificadas pelos testes de Coagulase, catalase e DNASE confirmando a presença de Estafilococos coagulase positiva, ou seja, Staphylococcus aureus. As análises foram realizadas no Laboratório de Microbiologia e

\footnotetext{
Referência:

Winnie Alencar Luciano, Roberta Santos Lima, Maiara da Costa Lima, Rhayane Idalyne Carvalho, Eryka Maria dos Santos Alves, Jossana Pereira de Sousa, Thais Santana Ribeiro, Evandro Leite de Souza, Maria Lúcia da Conceição. Estafilococos Coagulase Positiva em Amostras de Queijo Minas Frescal Vendidos em João Pessoa - Pb. In: Anais do 12 Congresso Latinoamericano de Microbiologia e Higiene de Alimentos - MICROAL 2014 [= Blucher Food Science Proceedings, num.1, vol.1]. São Paulo: Editora Blucher, 2014. DOI 10.5151/foodsci-microal-204
} 
Bioquímica de Alimentos do departamento de Nutrição do centro de Ciências da Saúde da Universidade Federal da Paraíba. Os resultados obtidos neste estudo revelaram que 13 (96,86\%) amostras estavam contaminadas por Estafilococos. Na marca R1 obteve-se contagens entre $6,78 \pm 0,00$ a $8,07 \pm 0,00$, na R2 de $6,48 \pm 0,00$ a $8,25 \pm 0,00$, na R3 6,04 $\pm 0,00$ a $8,01 \pm 0,00$, na R4 de $6,79 \pm 0,00$ a $8,23 \pm 0,00$ e na R5 entre $6,48 \pm 0,00$ e $7,51 \pm 0,00$. Confrontando-se os valores encontrados com a Legislação vigente verificou-se que todas as amostras estavam em desacordo com a legislação que fixa em $10^{3}\left(3 \log _{10} \mathrm{UFC} / \mathrm{g}\right)$ o limite máximo. Em termos conclusivos, constata-se que essas contagens despertam à possibilidade da produção de enterotoxinas, constituindo em um perigo eminente para a saúde do consumidor, tendo em vista, que todas as amostras estavam dentro do prazo de validade. Considerando a técnica empregada, ressalta-se a ótima reprodutividade da população microbiana e, por conseguinte, apta para o uso em laboratório.

Palavras-Chave: Contaminação, Estafilococos coagulase positiva, Queijo minas frescal

\section{Agência de Fomento:}

